\title{
Nutritional Evaluation, Characterization and Antioxidant Activity of Radix Isatidis Protein Hydrolysates under Simulated Gastrointestinal Digestion
}

\author{
Ping Xiao", Hongzhi Huang", Yayun Chen, Jianwei Chen, Xiang Li*, Haitao Shi \\ College of Pharmacy, Nanjing University of Chinese Medicine, Nanjing, P.R. China \\ \# These authors contributed equally to this work and should be considered co-first authors. \\ *Corresponding author: lixiang_8182@163.com
}

Received September 01, 2014; Revised October 20, 2014; Accepted October 27, 2014

\begin{abstract}
In this study, the antioxidant activities of alcalase-treated Radix Isatidis protein hydrolysates (RIPH) were compared during a two-stage gastrointestinal (GI) digestion in vitro. Compared with the blank, the enzymatic breakdown of the GI digests increased their 1,1-diphenyl-2-picrylhydrazyl (DPPH) (1.2-fold increase), hydroxyl (1.9-fold increase), superoxide anion (5.6-fold increase) in the radical scavenging activities and the reducing power (4.0-fold increase). The investigated items of RIPH consisted of the degrees of hydrolysis (DH), the compositions of amino acid, the nutritional parameters and the molecular weight distributions (MWD). The analysis of amino acid compositions of RIPH showed that essential amino acids such as isoleucine, threonine, tryptophan, valine and histidine took a high portion. The final Radix Isatidis protein hydrolysate digests (FRIPHD) contained the free amino acids of about $29.4 \%$. Results from this study showed that RIPH is a good source of natural antioxidants that the formed peptides can resist physiological digestion in GI digestive system.
\end{abstract}

Keywords: radix isatidis protein, hydrolysates; gastrointestinal digestion, antioxidant activity, amino acid composition

Cite This Article: Ping Xiao, Hongzhi Huang, Yayun Chen, Jianwei Chen, Xiang Li, and Haitao Shi, "Nutritional Evaluation, Characterization and Antioxidant Activity of Radix Isatidis Protein Hydrolysates under Simulated Gastrointestinal Digestion.” Journal of Food and Nutrition Research, vol. 2, no. 11 (2014): 831-838. doi: 10.12691/jfnr-2-11-12.

\section{Introduction}

Radix Isatidis, commonly known as Ban-Lan-Gen in China, is the dry root of plant Isatis indigotica Fortune (family Cruciferae). It is an ancient dye and medicinal herb which was widely cultivated in Europe from the 12th to the 17th century as a source of indigo [1]. Radix Isatidis has already become an important commercial crop for farmers widely distributed and cultivated in China. It was firstly documented as the herbal drug in The Divine Husbandman's Herbal Foundation Canon, a famous ancient medical book in the Han Dynasty of China (200 $\mathrm{AD}$ ). Radix Isatidis has been used in the treatment of cold, sore throat and headache for hundreds of years in China $[2,3]$. Because of its unique medicinal properties such as preventing the influenza virus infection, enhancing body immunity and detoxicating $[4,5,6]$, Radix Isatidis has been developed into various beverages which are widely welcomed in China $[7,8]$.

Food proteins may act as sources of bioactive peptides. These peptides are encrypted in the proteins and can be released in vitro during the food processing or in vivo by the gastrointestinal digestion. Bioactive peptides can exert their effects on the gastrointestinal system or be absorbed through the intestinal tract and act on important systems [9]. Recently, bioactive peptides, derived from food sources, have catched more and more attraction for the prevention and treatment of different diseases such as cancer, arthrosclerosis, coronary heart diseases and diabetes mellitus [10]. Antioxidative peptides are one of the research hotspots in food science because of their antioxidant properties [11].

In vitro methods for simulating the human digestive tract are being used extensively since they are rapid, inexpensive, safe, reproducible and do not have the same ethical restrictions as in vivo methods [12,13]. These methods have been used to evaluate the antioxidant effects of anthocyanins [14,15], phenolics [16] and flavanones [17]. Some food proteins and protein hydrolysates have been reported to have antioxidant capacity $[18,19,20]$. Proteins in raw and processed food can possess antioxidant peptide sequences and structural domains and the active fragments are released during the GI digestion process [21].

Radix Isatidis protein as a macromolecular compound may possess antioxidant peptide sequences. In the process of traditional Chinese medicine (TCM) preparations, the protein was always discarded. Previous antioxidant activity researches of Radix Isatidis only focused on polysaccharides [22,23]. Whether the Radix Isatidis 
protein also has antioxidant activities as polysaccharides, it is not clear. Hence, it presents great significance to investigate the antioxidant activities of Radix Isatidis protein. In this study, the antioxidant activities of Radix Isatidis protein hydrolysates (RIPH) subjected to a simulated GI digestion were investigated for the first time, and the degree of hydrolysis (DH), the molecular weight distributions (MWD), the amino acid compositions of RIPH were also determined.

\section{Materials and Methods}

\subsection{Materials and Chemicals}

Radix Isatidis was purchased from a medical market in Tongling city of Anhui province (China). The botanical origin was identified by Professor Jianwei Chen, Nanjing University of Chinese Medicine. The voucher specimens were deposited at the Herbarium in Nanjing University of Chinese Medicine (Nanjing, China).

Pepsin from porcine gastric mucosa, pancreatin from porcine pancreas and bile salts (mixture of sodium cholate and sodium deoxycholate) were purchased from Shanghai Solarbio Biosience \& Techology Co., Ltd. (Shanghai, China). The cellulose dialysis tubing (molecular mass cut off, 1000 Da) was obtained from Yuan Ye Biotechnology Co., Ltd. (Shanghai, China). The formic acid and acetonitrile were purchased from Merck (Darmstadt, Germany). Ammonium formate (analytical grade) was purchased from Shanghai Chemical Reagent Factory (Shanghai, China). 1,1-diphenyl-2-picrylhydrazyl (DPPH) was obtained from Aladdin (Shanghai, China). Vitamin C and other chemicals were purchased from Sinopharm Chemical Reagent Co., Ltd. (Shanghai, China). Deionized water was prepared using a Millipore MilliQ-Plus system (Millipore, Bedford, MA). The solvents and chemicals used were of analytical grade or HPLC grade.

\subsection{Preparation of Radix Isatidis Proteins}

To obtain the Radix Isatidis proteins, take about $50 \mathrm{~g}$ Radix Isatidis powder mixed with $1000 \mathrm{~mL} 50 \mathrm{mM}$ Tris$\mathrm{HCl}$ solution $(\mathrm{pH}=7.8)$ and then ultrasonic-assisted extracted for $60 \mathrm{~min}$ in a conical flask. The extracted solution was subsequently centrifuged at $3000 \mathrm{~g}$ for $5 \mathrm{~min}$. The supernatant was collected and then slowly added ammonium sulfate to $70 \%$ at $4^{\circ} \mathrm{C}$. The mixture was stored in $4^{\circ} \mathrm{C}$ refrigerator for $12 \mathrm{~h}$ whereafter centrifuged at $3500 \mathrm{~g}$ for $10 \mathrm{~min}$. Discarded the supermatant and the protein precipitation was collected. The protein was redissolved with distilled water and then fed into cellulose dialysis tubing to remove the remaining salt and small molecule compounds at $4^{\circ} \mathrm{C}$. The protein solution was dried by a vacuum freeze drier and then preserved in a refrigerator at $-20^{\circ} \mathrm{C}$ before use. About $70 \mathrm{mg}$ of lyophilized powder was obtained from 10 g Radix Isatidis.

\subsection{Preparation of Radix Isatidis Protein Hydrolysates (RIPH)}

In order to obtain the alcalase hydrolysate $(\mathrm{AH})$, Radix Isatidis protein solution $(5 \%, \mathrm{w} / \mathrm{v})$ at $\mathrm{pH} 8.0$ were hydrolyzed with alcalase at $45^{\circ} \mathrm{C}$ for $4 \mathrm{~h}$. The ratio of enzyme to protein substrate was $2 \%(w / w)$. The enzymatic hydrolysis was stopped by heating in boiling water for 15 min. Subsequently, the $\mathrm{pH}$ value was adjusted to 7.0 with $0.01 \mathrm{~mol} \mathrm{~L}^{-1} \mathrm{HCl}$. The hydrolysate was centrifugated at $10000 \mathrm{~g}$ for $15 \mathrm{~min}$ then the supernatant solution was lyophilized for further subsequent studies.

\subsection{In Vitro Simulated GI Digestion}

In vitro simulated GI digestion was carried out in accordance with the method of Cinq-Mars with a slight modification [13]. The RIPH were re-dissolved (5\% w/v, in distilled water) and adjusted to $\mathrm{pH} 2.0$ with $1 \mathrm{~mol} \mathrm{~L}^{-1}$ $\mathrm{HCl}$ followed by the addition of pepsin (4\%, w/w, protein basis). The mixture was incubated in a shaking water bath at $37^{\circ} \mathrm{C}$ for $2 \mathrm{~h}$. Then, the $\mathrm{pH}$ was adjusted to 5.3 with 0.9 mol L ${ }^{-1} \mathrm{NaHCO}_{3}$ solution. After the addition of pancreatin (4\% w/w, protein basis), the $\mathrm{pH}$ was adjusted to 7.5 with 1 $\mathrm{mol} \mathrm{L}{ }^{-1} \mathrm{NaOH}$. The mixture was further incubated at $37^{\circ} \mathrm{C}$ for another $2 \mathrm{~h}$. In order to terminate the digestion, the test tubes were kept in boiling water for $15 \mathrm{~min}$ to inactivate the enzymes. After these, the GI digests were cooled to room temperature and centrifuged at $12000 \mathrm{~g}$ for $10 \mathrm{~min}$. The supernatant was freeze dried and kept at $-20^{\circ} \mathrm{C}$ before use.

\subsection{Degree of Hydrolysis (DH)}

Degree hydrolysis of RIPH was determined according to the method of Spellman D [24]. The content of amino nitrogen was determined by a formaldehyde titration method (FTM). The total nitrogen content was estimated as explained by the Kjeldahl method [25].

\subsection{Amino Acid Analysis}

\subsubsection{Total Amino Acid (TAA) Analysis}

The samples (5 mg) were hydrolyzed with $5 \mathrm{~mL}$ of $6 \mathrm{~N}$ $\mathrm{HCl}$ for $24 \mathrm{~h}$ at $110^{\circ} \mathrm{C}$ in a sealed tube. The amino acid compositions of samples were determined by hydrophilic interaction ultra-high-performance liquid chromatography coupled with triple-quadrupole mass spectrometry (HILIC-UPLC-MS/MS) according to our previously developed method [26]. Alkaline hydrolysis was also adopted to determine tryptophan.

\subsubsection{Free Amino Acids (FAA) Analysis}

The GI digests were precipitated with $10 \%$ cold trichloroacetic acid for $2 \mathrm{~h}$ and then centrifuged at 12,000 $\mathrm{g}$ for $10 \mathrm{~min}$. The supernatant was filtered through a 0.22 $\mu \mathrm{m}$ polytetrafluoroethylene filter. The filtrate was subjected to UPLC-MS/MS to determine the free amino acid compositions according to the method of Pan [26].

\subsection{Evaluation of Nutritional Parameters}

The amino acid composition of sample was used for calculation of several nutritional parameters of RIPH and FRIPHD as summarized below [27].

a) The proportion of essential amino acids (E) to total amino acids $(\mathrm{T})$ of the protein:

$$
\frac{E}{T} \%=\left(\begin{array}{c}
\begin{array}{c}
\text { Ile+Leu+Lys+Met+Cys+Phe } \\
+ \text { Tyr+Thr+Val+His+Trp }
\end{array} \\
\begin{array}{l}
\text { Ala+Asp+Arg+Gly+Glu } \\
+ \text { Ile+Leu+Lys+Met+Cys+Phe } \\
+ \text { Tyr+Pro+Ser+Thr+Val+His+Trp }
\end{array}
\end{array}\right) \times 100
$$


b) Amino acid score:

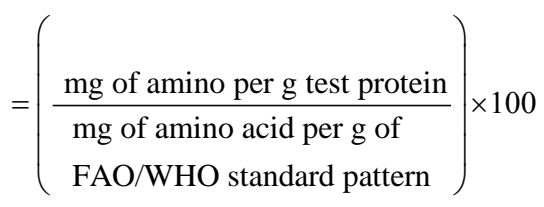

\subsection{Sodium Dodecyl Sulfate Polyacrylamide Gel Electrophoresis (SDS-PAGE)}

With some modifications of the method from Prandi, the RIPH and FRIPHD samples were analyzed by SDSPAGE [28]. Firstly, $100 \mu \mathrm{l}$ of the samples were mixed with the same volume of the samples buffer $(\mathrm{pH} 6.8 ; 1 \%$ SDS; $12.5 \%$ glycerol; $0.005 \%$ bromophenol blue; $2.5 \%$ 2mercaptoethanol). After denatured at $95^{\circ} \mathrm{C}$ for $5 \mathrm{~min}$, the samples were loaded into a Criterion bis-tris precast gels $12 \%$. Then, the runs were carried out in a Mini Protean II Dual Slab Cell (BIO-RAD). The running buffer was 25 mM Tris, $192 \mathrm{mM}$ glycine and 0.1\% SDS and the current intensity applied was $15 \mathrm{~mA}$. The gel was finally stained with Coomassie Brilliant Blue.

\subsection{Determination of Antioxidant Activities}

\subsubsection{DPPH Radical Scavenging Activity Assay}

Experiments were carried out as published method with some modifications [12]. Briefly, $2.0 \mathrm{~mL}$ of test sample mixed with $2.0 \mathrm{~mL}$ of $0.15 \mathrm{mM}$ DPPH were dissolved in 95\% ethanol. The reaction mixture was shaken well and incubated for $30 \mathrm{~min}$ at room temperature in the dark. The absorbance of the resulting solution was recorded at 517 $\mathrm{nm}$. The radical-scavenging activity (RSA) was calculated as a percentage of DPPH discoloration using the equation I $\%=\left[1-\left(A_{i}-A_{j}\right) / A_{0}\right] \times 100 \%$, where $A_{0}$ was the absorbance of the blank sample, $A_{i}$ was the absorbance in the presence of different test samples and $A_{j}$ was the absorbance of the blank reagent. Vitamin $C$ was used as a positive antioxidant control and the standard curves that correlated the concentration of vitamin $C$ (ranging from 1 to $150 \mathrm{mg} \mathrm{L}^{-1}$ ) and the amount of absorbance reduction caused by vitamin $\mathrm{C}$ were obtained. The results were calculated as $\mu \mathrm{g}$ of vitamin $\mathrm{C}$ equivalent antioxidant capacity (VCEAC) per mL of sample solution [15].

\subsubsection{Hydroxyl Radical Scavenging Activity Assay}

The hydroxyl radical-scavenging capacity was measured by a previously developed method with some modifications [12]. The reaction mixture was made of 0.5 $\mathrm{mL}$ of sample solution, $2.0 \mathrm{~mL}$ of $0.75 \mathrm{mM}$ phosphate buffer (pH 7.4), $1.0 \quad \mathrm{~mL} \quad 0.75 \quad \mathrm{mmol} \quad \mathrm{L}^{-1} \quad 1,10-$ phenanthroline ethanol solution and $1.0 \mathrm{~mL}$ of $0.75 \mathrm{mmol}$ $\mathrm{L}^{-1} \mathrm{FeSO}_{4}$. To initiate the reaction, $1.0 \mathrm{~mL}$ of $0.01 \%(\mathrm{v} / \mathrm{v})$ $\mathrm{H}_{2} \mathrm{O}_{2}$ were added. Then, the mixture was incubated for $1 \mathrm{~h}$ at $37^{\circ} \mathrm{C}$ and the absorbance was measured at $536 \mathrm{~nm}$ using a spectrophotometer. Hydroxyl radical-scavenging capacity was calculated according to the following equation: Hydroxyl radical scavenging capacity $(\%)=\left[\left(\mathrm{A}_{\mathrm{i}}\right.\right.$ $\left.\left.-A_{0}\right) /\left(A-A_{0}\right)\right] \times 100 \%$, where $A_{i}$ was the absorbance of samples, $\mathrm{A}_{0}$ was the absorbance of blank solution containing $\mathrm{H}_{2} \mathrm{O}_{2}$, A was the absorbance of control solution containing without $\mathrm{H}_{2} \mathrm{O}_{2}$ replaced with distilled water. The result was expressed as equivalent vitamin $\mathrm{C}$ as above.

\subsubsection{Superoxide Anion Radical Scavenging Activity}

Superoxide anion scavenging activity of samples was determined as described by Han with slight modifications [29]. Briefly, $1 \mathrm{~mL}$ of nitro blue tetrazolium (NBT) solution $\left(156 \mu \mathrm{mol} \mathrm{L}-1\right.$ NBT in $100 \mathrm{mmol} \mathrm{L}^{-1}$ phosphate buffer, $\mathrm{pH}$ 7.4), $1 \mathrm{~mL}$ nicotinamide-adenine dinucleotid (NADH) solution (468 $\mu \mathrm{mol} \mathrm{L}{ }^{-1} \mathrm{NADH}$ in $100 \mathrm{mmol} \mathrm{L}^{-1}$ phosphate buffer, $\mathrm{pH} 7.4$ ) and $0.1 \mathrm{~mL}$ of the samples were mixed. The reaction was started by adding $100 \mu \mathrm{L}$ of phenazine methosulphate (PMS) solution $\left(60 \mu \mathrm{mol} \mathrm{L}{ }^{-1}\right.$ PMS in $100 \mathrm{mmol} \mathrm{L}^{-1}$ phosphate buffer, $\mathrm{pH}$ 7.4) to the mixture. The reaction mixture was incubated at $25^{\circ} \mathrm{C}$ for $5 \mathrm{~min}$, and the absorbance at $560 \mathrm{~nm}$ was measured against blank samples. The positive control (vitamin C) and the negative control (only the solvent was added) were subjected to the same procedures described above. All measurements were made in triplicate and averaged. The decreased absorbance of the reaction mixture indicates the increased superoxide anion scavenging activity. The percentage inhibition of superoxide anion generation was calculated by the following formula: scavenging rate $(\%)=\left(1-A_{i} / A_{0}\right) \times 100 \%$, where $A_{0}$ is the absorbance without sample, and $\mathrm{A}_{\mathrm{i}}$ is absorbance with sample. The antioxidant activity was expressed as above.

\subsubsection{Reducing Power Assay}

An experiment was carried out according to the method of Benzie \& Szeto with some modifications in 96-well microplates $(n=6)$ [30]. The working FRAP reagent was produced by mixing $300 \mathrm{mM}$ acetate buffer ( $\mathrm{pH}$ 3.6), 10 mmol L ${ }^{-1}$ TPTZ solution and $20 \mathrm{mmol} \mathrm{L}^{-1} \mathrm{FeCl}_{3} \cdot 6 \mathrm{H}_{2} \mathrm{O}$ in a ratio of $10: 1: 1$ just before use and heated to $37^{\circ} \mathrm{C}$. The TPTZ solution was prepared by making a solution of 10 mmol L ${ }^{-1} \mathrm{TPTZ}$ in $40 \mathrm{mmol} \mathrm{L}^{-1} \mathrm{HCl}$. A reaction volume of $200 \mu \mathrm{L}$ containing $150 \mu \mathrm{L}$ working FRAP reagent, 30 $\mu \mathrm{L}$ acetate buffer and $20 \mu \mathrm{L}$ sample was incubated at room temperature for $10 \mathrm{~min}$ and the absorbance was recorded at $593 \mathrm{~nm}$. An increased absorbance of the reaction mixture indicated increased reducing power.

\subsection{Statistical Analysis}

All the tests were conducted in triplicate. Results were expressed as the mean values \pm standard deviation (S.D.). The results were analyzed by SPSS 13.0 software (SPSS Inc., Chicago, IL, USA). Significance $(\mathrm{P}<0.05)$ among the means was determined by one-way ANOVA.

\section{Results and Discussion}

\subsection{The DH of GI Digests}

As shown in Figure 1, the DH of non-digested RIPH (0 h) was $20.54 \pm 1.84 \%$. After digested by pepsin for $2 \mathrm{~h}$, the $\mathrm{DH}$ increased slightly $(\mathrm{P}>0.05)$. However, further incubation with pancreatin (from 2.0 to $4.0 \mathrm{~h}$ ) produced a dramatic increase in $\mathrm{DH}$ from $24.82 \pm 2.31 \%$ to $44.49 \pm$ $2.15 \%(\mathrm{P}<0.05)$. Pepsin, a kind of endopeptidases, can be prior to cleave the C-terminal of Phe, Tyr and Trp. Pancreatin consists of trypsin, elastase, chymotrypsin and carboxypeptidases, which function together to cleave the polypeptides into oligopeptides and amino acids. This could be a possible reason accounting for the trend of $\mathrm{DH}$ during GI digestion in vitro. Obviously, most of the 
peptides may be hydrolysed into smaller peptides and possibly amino acids during sequential digestion with pepsin and pancreatin.

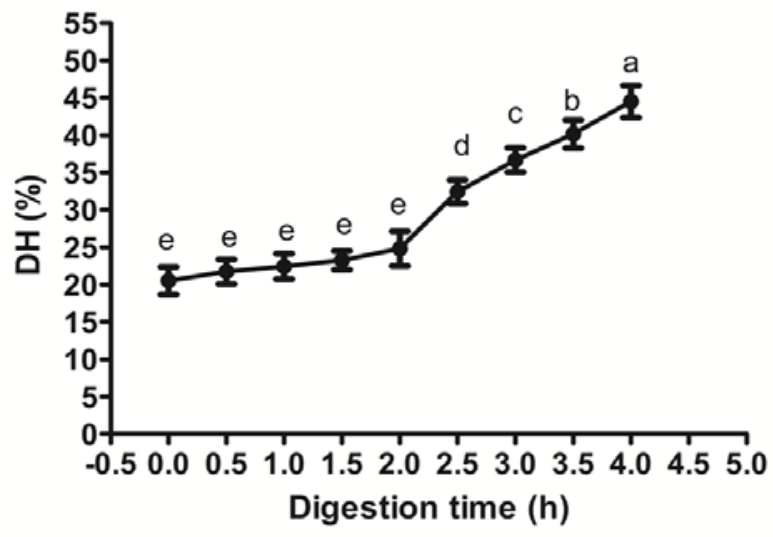

Figure 1. Changes in DH during sequential in vitro digestion of Radix Isatidis protein hydrolysate (RIPH). The first stage: from 0.0 to $2.0 \mathrm{~h}$, digested by pepsin; the second stage: from 2.0 to $4.0 \mathrm{~h}$, digested by pancreatin. The data with different lowercase letters are significantly ( $P$ $<0.05)$ different.

\subsection{The Amino Acids of GI Digests}

The amino acid compositions (g/100 g protein) of RIPH and FRIPHD were presented in Table 1. The daily amounts of the essential amino acids for 2-5 years old recommended by FAO/WHO were also included [31]. RIPH and FRIPHD were both rich in isoleucine, valine, aspartic acid, glutamic acid, arginine and proline. Isoleucine, threonine, tryptophan, valine and histidine of RIPH and FRIPHD met the FAO/WHO requirements. However, leucine, lysine, total sulphur and aromatic amino acids did not reach the minimum FAO requirements. The total essential amino acids in RIPH (33.34 g/100 g) and in FRIPHD (30.11 g/100 g) almost met the requirements $(32.80 \mathrm{~g} / 100 \mathrm{~g})$. The amounts of sulfur-containing amino acids (methionine and cysteine) in FRIPHD were remarkably higher than that of RIPH (Table 1). Antioxidant amino acids (AAA) contain hydrophobic amino acids (valine, alanine, proline and leucine), aromatic amino acids (tyrosine, histidine, and phenylanine), and methionine [32]. AAA might control antioxidant potentials of proteins and peptides [33]. The content of AAA of FRIPHD (30.84 g/100 g) was relatively higher than that of RIPH (24.49). The proportion of essential amino acids to the total amino acids (E/T) for RIPH was higher than that of FRIPHD, suggesting that the RIPH has more nutritional amino acid pattern than that of FRIPHD.

Table 1. Total amino acid compositions (g/100g protein) of RIPH and FRIPHD, and the FAO/WHO suggested requirements (2-5 years old) for essential amino acids. Data are average \pm standard deviation $(n=3)$

\begin{tabular}{cccc}
\hline Amino acids & RIPH & FRIPHD & FAO/WHO suggested \\
\hline Isoleucine & $5.48 \pm 0.12$ & $3.43 \pm 0.06$ & 6.6 \\
Leucine & $2.67 \pm 0.05$ & $3.69 \pm 0.17$ & 5.8 \\
Lysine & $0.86 \pm 0.04$ & $0.53 \pm 0.02$ & \\
Cysteine & $0.15 \pm 0.02$ & $0.03 \pm 0.00$ & $1.29 \pm 0.19$ \\
Methionine & $0.14 \pm 0.01$ & $2.57 \pm 0.21$ & 3.4 \\
Tyrosine & $0.42 \pm 0.06$ & $3.59 \pm 0.36$ & 1.1 \\
Phenylalanine & $3.15 \pm 0.24$ & $3.61 \pm 0.21$ & 3.5 \\
Threonine & $5.12 \pm 0.37$ & $1.86 \pm 0.09$ & 1.9 \\
Tryptophan & $7.57 \pm 0.41$ & $4.08 \pm 0.61$ & \\
Valine & $4.82 \pm 0.24$ & $5.43 \pm 0.34$ & \\
Histidine & $2.96 \pm 0.03$ & $9.32 \pm 0.72$ & \\
Arginine & $5.64 \pm 0.41$ & $4.98 \pm 0.31$ & \\
Aspartic acid + asparagine & $11.82 \pm 0.26$ & $4.95 \pm 0.24$ & \\
Glutamic acid + glutamine & $6.03 \pm 0.13$ & $9.13 \pm 0.57$ & \\
Serine & $3.84 \pm 0.04$ & $0.42 \pm 0.02$ & \\
Proline & $8.88 \pm 0.35$ & $1.06 \pm 0.04$ & 1.32 \\
Glycine & $6.79 \pm 0.18$ & 6.16 & 3.3 \\
Alanine & $1.45 \pm 0.02$ & 30.11 & 32.8
\end{tabular}

${ }^{\mathrm{a}}$ The proportion of essential amino acids to the total amino acids.

bAAA, antioxidant amino acids, it contains hydrophobic amino acids (valine, alanine, proline and leucine), aromatic amino acids (tyrosine, histidine, and phenylanine), and methionine.

From the statistics given in Table 2, it can be seen that the content of FAA increased rapidly from 0 to $4 \mathrm{~h}$ (from 80.19 to $230.18 \mathrm{mg} \mathrm{g}^{-1}$ ). After the pepsin digestion, the content of FAA increased by $73 \%$ compared to the blank $(0 \mathrm{~h})$. However, the further two hours incubation with pancreatin increased the content of FAA by $187 \%$. It can be concluded that the peptides were mainly broken into

small fragments instead of free amino acids during pepsin digestion. After the digestion with pancreatin, these peptides were more completely hydrolysed. This corollary was consistent with the previous research of loach protein [12]. At the end of GI digestion $(4.0 \mathrm{~h})$, less than $30 \%$ of the digests were comprised of FAA. Thus, most of the digests still remained in the form of peptides, which might 
contribute to the antioxidant activities in vitro as described later.

Table 2. Changes in the free amino acids (FAA) content in Radix Isatidis protein hydrolysates (RIPH) during sequential in vitro digestion

\begin{tabular}{|c|c|c|c|c|c|c|c|c|c|}
\hline \multirow{2}{*}{ Amino acids } & \multicolumn{9}{|c|}{ FAA (mg amino acid/g GI digest powder) } \\
\hline & $0 \mathrm{~h}$ & $0.5 \mathrm{~h}$ & $1.0 \mathrm{~h}$ & $1.5 \mathrm{~h}$ & $2.0 \mathrm{~h}$ & $2.5 \mathrm{~h}$ & $3.0 \mathrm{~h}$ & $3.5 \mathrm{~h}$ & $4.0 \mathrm{~h}$ \\
\hline Isoleucine & 6.08 & 6.25 & 7.56 & 8.19 & 9.15 & 9.26 & 10.24 & 11.47 & 12.56 \\
\hline Leucine & 3.14 & 4.45 & 5.98 & 6.16 & 7.15 & 7.56 & 8.98 & 10.13 & 11.28 \\
\hline Lysine & 1.65 & 1.88 & 1.99 & 2.08 & 2.15 & 2.47 & 2.49 & 3.15 & 3.78 \\
\hline Cysteine & 0.14 & 0.16 & 0.18 & 0.19 & 0.2 & 0.21 & 0.24 & 0.35 & 0.44 \\
\hline Methionine & 3.66 & 3.71 & 4.74 & 5.82 & 7.12 & 9.17 & 9.48 & 10.67 & 11.67 \\
\hline Tyrosine & 0.75 & 1.21 & 1.47 & 1.56 & 1.84 & 1.96 & 2.24 & 2.58 & 3.04 \\
\hline Phenylalanine & 5.45 & 9.15 & 9.87 & 9.98 & 12.24 & 12.89 & 13.14 & 13.52 & 14.37 \\
\hline Threonine & 0.18 & 0.19 & 0.19 & 0.24 & 0.26 & 0.27 & 0.29 & 0.34 & 0.39 \\
\hline Tryptophan & 4.23 & 4.52 & 4.58 & 4.64 & 4.94 & 5.16 & 6.28 & 7.25 & 7.64 \\
\hline Valine & 7.89 & 8.25 & 8.28 & 8.64 & 9.14 & 9.67 & 10.26 & 12.18 & 13.47 \\
\hline Histidine & 6.67 & 7.26 & 8.56 & 10.28 & 12.45 & 13.27 & 15.17 & 16.29 & 18.48 \\
\hline Arginine & 3.46 & 4.25 & 4.74 & 5.79 & 6.28 & 6.96 & 7.52 & 7.94 & 8.62 \\
\hline Aspartic acid + asparagine & 18.24 & 20.15 & 22.54 & 30.98 & 32.67 & 52.15 & 58.47 & 64.19 & 71.56 \\
\hline Glutamic acid + glutamine & 6.52 & 9.12 & 10.24 & 11.17 & 14.45 & 16.17 & 18.54 & 19.71 & 26.49 \\
\hline Serine & 6.18 & 6.24 & 7.49 & 7.84 & 9.27 & 10.14 & 11.42 & 12.53 & 13.82 \\
\hline Proline & 4.56 & 5.17 & 6.21 & 6.48 & 7.34 & 8.26 & 8.47 & 9.15 & 9.84 \\
\hline Glycine & 1.15 & 1.18 & 1.56 & 1.64 & 1.68 & 1.74 & 1.78 & 1.81 & 2.06 \\
\hline Alanine & 0.24 & 0.25 & 0.28 & 0.29 & 0.35 & 0.37 & 0.38 & 0.49 & 0.67 \\
\hline AAA & 32.36 & 39.45 & 45.39 & 49.21 & 57.63 & 63.15 & 68.12 & 75.01 & 82.82 \\
\hline Total & 80.19 & 93.39 & 106.46 & 121.97 & 138.68 & 167.68 & 185.39 & 203.75 & 230.18 \\
\hline
\end{tabular}

\subsection{SDS-PAGE Analysis}

As a common way to analyse molecular characterization of protein samples, SDS-PAGE was performed to evaluate different molecular proteins. The SDS-PAGE profiles of protein constituents of RIPH and FRIPHD are showed in Figure 2. The main molecules contained in RIPH sample weight about $24.8 \mathrm{kDa}$ and $40.0 \mathrm{kDa}$. The FRIPHD sample also has the two bands, but the color is more shallow than RIPH. After simulated GI digestion, the electrophoretic profiles of RIPH and FRIPHD showed some differences which evidenced the different molecular peptides existed in each sample. The diminution of the total intensity of the RIPH sample in the gel suggested that most peptides produced by GI digestion had a lower molecular weight than the detection limit of this gel.

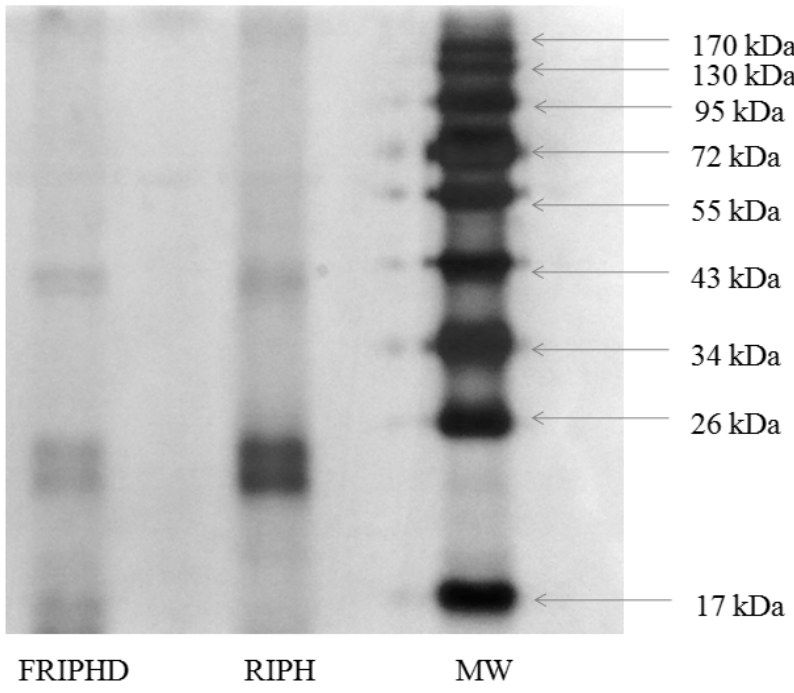

Figure 2. SDS-PAGE of Radix Isatidis protein hydrolysates (RIPH) and final Radix Isatidis protein hydrolysates digests (FRIPHD)

\subsection{The Antioxidant Activities of the GI Digests}

3.4.1. DPPH Radical Scavenging Activity
As shown in Figure 3A, the DPPH radical scavenging activity of the RIPH was $44.97 \pm 4.52 \mu \mathrm{g} \mathrm{mL}{ }^{-1}$ VCEAC at beginning. After pepsin digestion for $2.0 \mathrm{~h}$, the DPPH radical scavenging activity dramatically increased to $164.58 \pm 3.78 \mu \mathrm{g} \mathrm{mL}^{-1}(\mathrm{P}<0.05)$. However, the $\mathrm{DPPH}$ scavenging activity fell spectacularly to $117.64 \pm 4.26 \mu \mathrm{g}$ $\mathrm{mL}^{-1}$ VCEAC by $0.5 \mathrm{~h}$ pancreatin digestion. Further incubation with pancreatin for another $1.5 \mathrm{~h}$, the DPPH radical scavenging activity decreased steadily. During the pepsin digestion, a lot of hydrophobic amino residue side chain groups were expected to be exposed, which would make the peptides more accessible to the DPPH radicals and allow them to trap the radical more easily. However, the increased polarity of the GI digest makes it more difficult to react with the lipid-soluble DPPH radicals during the pancreatin digestion. [34] Of course, antioxidative amino acids might contribute to the antioxidant activities of the GI digests. As shown in Table 2 , the content of the antioxidative amino acids in the digests increased from 32.36 to $82.82 \mathrm{mg} \mathrm{g}^{-1}$. These antioxidative amino acids could act as proton/electron donors and quench the free radical, resulting in enhanced DPPH radical scavenging activity during digestion [35]. These could be some possible reasons of why the DPPH radical scavenging activity increased markedly during the pepsin treatment, but decreased slightly by pancreatin digestion.

\subsubsection{Hydroxyl Radical Scavenging Activity}

In the hydroxyl radical scavenging test (Figure 3B), the scavenging activity of RIPH improved with the digestion time extended. After digestion by pepsin from the period of 0 to $2.0 \mathrm{~h}$, the hydroxyl radical scavenging activity of the GI digests did not show a significant change. However, the hydroxyl radical activity of the GI digests sharply increased to $94.67 \pm 4.28 \mu \mathrm{g} \mathrm{mL}^{-1} \operatorname{VCEAC~}(\mathrm{P}<0.05)$ at $2.5 \mathrm{~h}$. In the Fenton reaction $\left(\mathrm{Fe}^{2+}+\mathrm{H}_{2} \mathrm{O}_{2} \rightarrow \mathrm{Fe}^{3+}+\cdot \mathrm{OH}+\right.$ $\mathrm{OH}^{-}$), the impact of $\cdot \mathrm{OH}$ on susceptible compounds could be restrained by either $\mathrm{Fe}^{2+}$ chelation or $\cdot \mathrm{OH}$ stabilisation or both. [21] Therefore, the strong $\cdot \mathrm{OH}$ scavenging activity of RIPH digested for $4 \mathrm{~h}$, may be attributed to the removal of free $\mathrm{Fe}^{2+}$ prooxidant and stabilisation of radicals through hydrogen or electron donation [36]. 

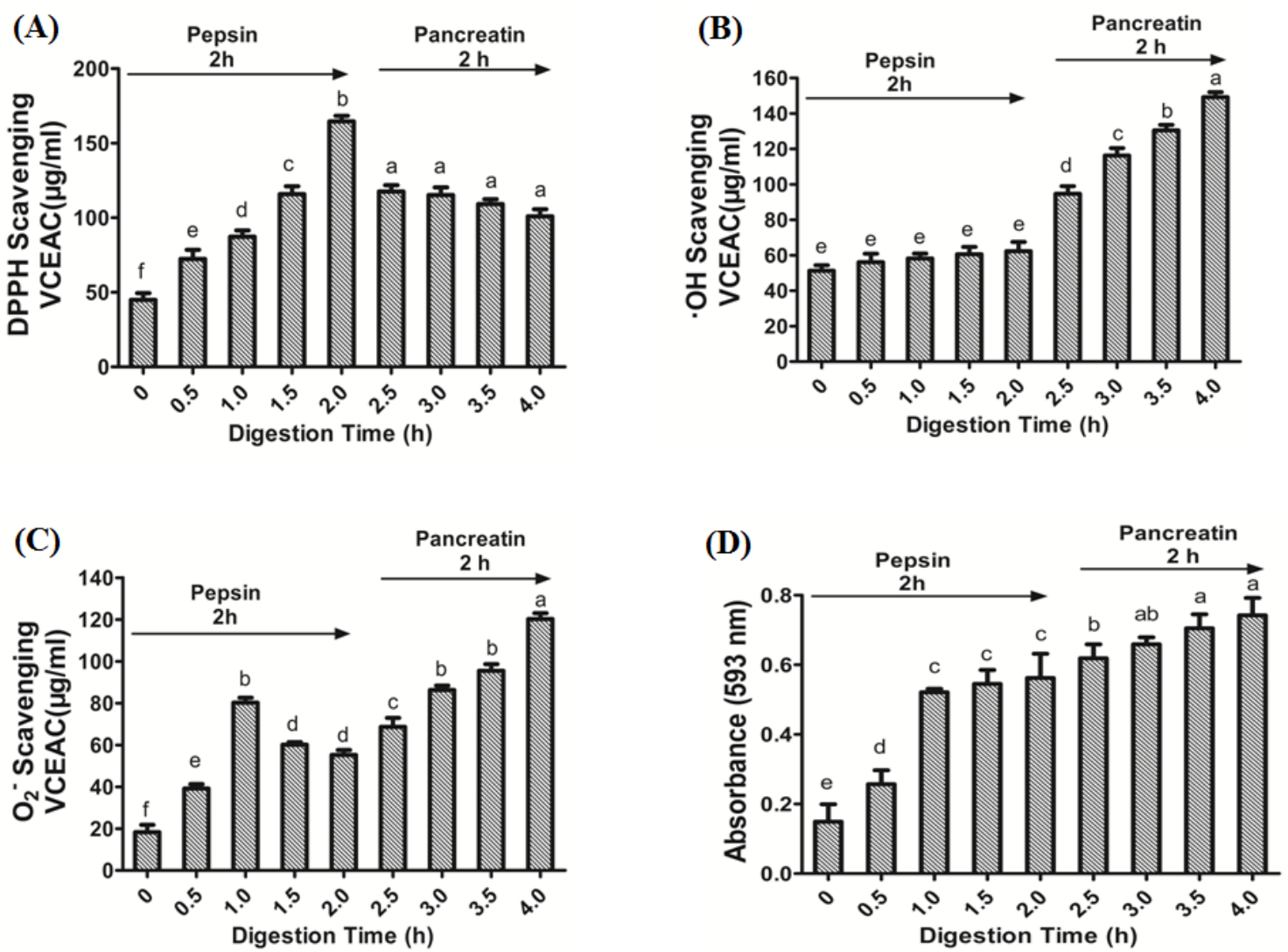

Figure 3. Changes in DPPH (A), hydroxyl (B), and superoxide anion (C) radical scavenging activity and reducing power (D) of Radix Isatidis protein hydrolysates (RIPH) during sequential in vitro digestion. The data with different lowercase letters in the same test are significantly $(\mathrm{P}<0.05)$ different.

\subsubsection{Superoxide Anion Radical Scavenging Activity}

Superoxide anion radical is one of the most important and biologically relevant reactive oxygen species (ROS) radicals in living organisms. It is a precursor to active free radicals that have the potential of reacting with biological macromolecules and thereby inducing tissue damage [37]. The superoxide anion radical scavenging activity of GI digests was shown in Figure 3C. The VCEAC of GI digests increased rapidly $(\mathrm{P}<0.05)$ and reached $80.23 \pm$ $2.35 \mu \mathrm{g} \mathrm{mL}^{-1}$ VCEAC for $1 \mathrm{~h}$ digestion by pepsin, then decreased with further incubation for another $1 \mathrm{~h}$ with pepsin. That was because during the initial stage of digestion, the increasing radical scavenging ability was attributed to a large number certain amino acids residues or short peptides. Then the increased hydrophobic properties of GI digests made them difficult to react with superoxide anion radical. The second stage of $2 \mathrm{~h}$ digestion by pancreatin brought a significant increase in superoxide anion radical scavenging activity $(\mathrm{P}<0.05)$. That was because the hydrophilic property of GI digests increased after digestion by pancreatin favoured their trapping of the superoxide anion radical. Also, the content of antioxidative amino acids was another important factor.

\subsubsection{Reducing Power}

As shown in Figure 3D, the reducing power of the blank was $0.149 \pm 0.05$. Then it significantly increased $(\mathrm{P}<0.05)$ to $0.521 \pm 0.01$ after $1.0 \mathrm{~h}$ of pepsin digestion. No significant increase was observed over the next $1 \mathrm{~h}$ $(\mathrm{P}>0.05)$. After $0.5 \mathrm{~h}$ of pancreatin digestion, the reducing power increased to $0.619 \pm 0.04(\mathrm{P}<0.05)$. Incubation for another $1.5 \mathrm{~h}$ with pancreatin did not bring any obvious changes in the reducing power $(\mathrm{P}>0.05)$. The final GI digests (FRIPHD) had a considerable increase in reducing power compared to the GI digests at $0 \mathrm{~h}$ (RIPH). The results indicated that the RIPH obtained more effective hydrogen or electron donors during GI digestion. The result was in accordance with the publication of You et al. that the reducing power of loach protein hydrolysate significantly increased after the treatment of pepsin and pancreatin for both $2 \mathrm{~h}$ [12]. With the increasing of $\mathrm{DH}$, numerous electron-dense amino acid side residue chain groups became more exposed during the process of GI digestion. The increased free amino acid and peptide scissions provided an additional source of electrons and protons to maintain a high redox potential.

\section{Conclusion}

The results at present showed that the antioxidant activities of RIPH enhanced with the GI digestion significantly. The amino acid compositions of RIPH and GI digestion samples were analyzed by HILIC-UPLCMS/MS successfully. After the RIPH conducted by simulated gastrointestinal digestion, the amounts of free amino acids greatly increased. The antioxidant ability of protein hydrolysates or peptides may have a good correlation with certain amino acids residues or short peptides. Further studies of antioxidant activities of RIPH in vivo are being done in our laboratory. However, this study provides a first approach to the evaluation of RIPH as ingredients to formulate functional foods with antioxidant activities. 


\section{Acknowledgements}

The financial grants of this work have been supported by NSFC (No. 81073023), the Project Funded by the Priority Academic Program Development of Jiangsu Higher Education Institutions (ysxk-2010) and 2013 Program sponsored for scientific innovation research of college graduate in Jiangsu province (CXZZ13_0631).

\section{References}

[1] Oberthur, C., Graf, H., and Hamburger, M. (2004). The content of indigo precursors in Isatis tinctoria leaves--a comparative study of selected accessions and post-harvest treatments. Phytochemistry. 65: 3261-3268.

[2] Ho, Y. L., and Chang, Y. S. (2002). Studies on the antinociceptive, anti-inflammatory and anti pyretic effects of Isatis indigotica root. Phytomedicine. 9: 419-424.

[3] Chung, Y. C., Tang, F. Y., Liao, J. W., Chung, C. H., Jong, T. T., and Chen, S. S., et al. (2011). Isatis indigotica induces hepatocellular cancer cell death via caspase-independent apoptosis-inducing factor translocation apoptotic pathway in vitro and in vivo. Integr Cancer Ther. 10: 201-214.

[4] Fang, J. G., Liu, Y. H., Wang, W. Q., Xie, W., Fang, S. X., and Han, H. G. (2005). The anti-endotoxic effect of o-aminobenzoic acid from Radix Isatidis. Acta Pharmacol Sin. 26: 593-597.

[5] Zhou, W., and Zhang, X. Y. (2013). Research Progress of Chinese Herbal Medicine Radix isatidis (Banlangen). AMERICAN JOURNAL OF CHINESE MEDICINE. 41: 743-764.

[6] Yang, Z., Wang, Y., Zhong, S., Zhao, S., Zeng, X., and Mo, Z., et al. (2012). In vitro inhibition of influenza virus infection by a crude extract from Isatis indigotica root resulting in the prevention of viral attachment. Mol Med Rep. 5: 793-799.

[7] Ruan H. S., and Li W. (2010). Preparation of solid beverage of effervescent tablet from Radix Isatidis. J Anhui Agric Sci. 38:3712-3713.

[8] Cheng Y. W., Li Y. H., Feng A. Q., Yi L., Wang L. Y., and Feng H. Y. (2012). Preparation of compound beverage containing Radix Isatidis and mung bean sprout juice. J. Henan Univ Technol. 33:82-84.

[9] Delgado, M., Tironi, V. A., and Anon, M. C. (2011). Antioxidant activity of amaranth protein or their hydrolysates under simulated gastrointestinal digestion. LWT-FOOD SCIENCE AND TECHNOLOGY. 44: 1752-1760.

[10] Chandrasekara, A., and Shahidi, F. (2011). Inhibitory Activities of Soluble and Bound Millet Seed Phenolics on Free Radicals and Reactive Oxygen Species. J Agric Food Chem. 59: 428-436.

[11] Memarpoor-Yazdi, M., Mahaki, H., and Zare-Zardini, H. (2013). Antioxidant activity of protein hydrolysates and purified peptides from Zizyphus jujuba fruits. JOURNAL OF FUNCTIONAL FOODS. 5: 62-70.

[12] You, L. J., Zhao, M., Regenstein, J. M., and Ren, J. Y. (2010). Changes in the antioxidant activity of loach (Misgurnus anguillicaudatus) protein hydrolysates during a simulated gastrointestinal digestion. Food Chem. 120: 810-816.

[13] Cinq-Mars, C. D., Hu, C., Kitts, D. D., and Li-Chan, E. (2008). Investigations into inhibitor type and mode, simulated gastrointestinal digestion, and cell transport of the angiotensin IConverting enzyme-inhibitory peptides in pacific hake (Merluccius productus) fillet hydrolysate. J Agric Food Chem. 56: 410-419.

[14] Bouayed, J., Hoffmann, L., and Bohn, T. (2011). Total phenolics, flavonoids, anthocyanins and antioxidant activity following simulated gastro-intestinal digestion and dialysis of apple varieties: Bioaccessibility and potential uptake. Food Chem. 128: 14-21.

[15] Liang, L. H., Wu, X. Y., Zhao, T., Zhao, J. L., Li, F., and Zou, Y., et al. (2012). In vitro bioaccessibility and antioxidant activity of anthocyanins from mulberry (Morus atropurpurea Roxb.) following simulated gastro-intestinal digestion. FOOD RESEARCH INTERNATIONAL. 46: 76-82.

[16] Nderitu, A. M., Dykes, L., Awika, J. M., Minnaar, A., and Duodu, K. G. (2013). Phenolic composition and inhibitory effect against oxidative DNA damage of cooked cowpeas as affected by simulated in vitro gastrointestinal digestion. Food Chem, 141: 1763-1771.

[17] Gil-Izquierdo, A., Gil, M. I., Tomas-Barberan, F. A., and Ferreres, F. (2003). Influence of industrial processing on orange juice flavanone solubility and transformation to chalcones under gastrointestinal conditions. J. Agric. Food Chem. 51: 3024-3028.

[18] Qian, Z. J., Jung, W. K., Byun, H. G., and Kim, S. K. (2008). Protective effect of an antioxidative peptide purified from gastrointestinal digests of oyster, Crassostrea gigas against free radical induced DNA damage. Bioresour Technol. 99: 3365-3371.

[19] Jung, W. K., Qian, Z. J., Lee, S. H., Choi, S. Y., Sung, N. J., and Byun, H. G., et al. (2007). Free radical scavenging activity of a novel antioxidative peptide isolated from in vitro gastrointestinal digests of Mytilus coruscus. J Med Food, 10: 197-202.

[20] Hernandez-Ledesma, B., Amigo, L., Ramos, M., and Recio, I. (2004). Angiotensin converting enzyme inhibitory activity in commercial fermented products. Formation of peptides under simulated gastrointestinal digestion. J Agric Food Chem. 52: 1504-1510.

[21] Ma, Y., Xiong, Y. L., Zhai, J., Zhu, H., and Dziubla, T. (2010). Fractionation and evaluation of radical-scavenging peptides from in vitro digests of buckwheat protein. Food Chem. 118: 582-588.

[22] Han, J. W., Jiang, X. M., and Zhang, L. D. (2011). Optimisation of extraction conditions for polysaccharides from the roots of Isatis tinctoria L. by response surface methodology and their in vitro free radicals scavenging activities and effects on IL-4 and IFNgamma mRNA expression in chicken lymphocytes. CARBOHYDRATE POLYMERS. 86: 1320-1326

[23] Du, Z. J., Liu, H., Zhang, Z. L., and Li, P. (2013). Antioxidant and anti-inflammatory activities of Radix Isatidis polysaccharide in murine alveolar macrophages. Int. J Biol. Macromol. 58: 329-335.

[24] Spellman, D., McEvoy, E., O'Cuinn, G., and FitzGerald, R. J. (2003). Proteinase and exopeptidase hydrolysis of whey protein: Comparison of the TNBS, OPA and $\mathrm{pH}$ stat methods for quantification of degree of hydrolysis. INTERNATIONAL DAIRY JOURNAL. 13: 447-453.

[25] Liu, C., Wang, H. L., Cui, Z. M., He, X. L., Wang, X. S., and Zeng, X. X., et al. (2007). Optimization of extraction and isolation for $11 \mathrm{~S}$ and $7 \mathrm{~S}$ globulins of soybean seed storage protein. Food Chem. 102: 1310-1316.

[26] Pan, Y. L., Li, J., Li, X., Chen, J. W., and Bai, G. G. (2014). Determination of Free Amino Acids in Isatidis Radix By HILICUPLC-MS/MS. BULLETIN OF THE KOREAN CHEMICAL SOCIETY. 35: 197-203.

[27] Chavan, U. D., McKenzie, D. B., and Shahidi, F. (2001). Protein classification of beach pea (Lathyrus maritimus L.). Food Chem. 75: 145-153.

[28] Prandi, B., Bencivenni, M., Faccini, A., Tedeschi, T., Dossena, A., and Marchelli, R., et al. (2012). Composition of peptide mixtures derived from simulated gastrointestinal digestion of prolamins from different wheat varieties. JOURNAL OF CEREAL SCIENCE. 56: 223-231.

[29] Han, T., Cheng, G., Liu, Y., Yang, H., Hu, Y. T., and Huang, W. (2012). In vitro evaluation of tectoridin, tectorigenin and tectorigenin sodium sulfonate on antioxidant properties. Food Chem Toxicol. 50: 409-414.

[30] Benzie, I. F., and Szeto, Y. T. (1999). Total antioxidant capacity of teas by the ferric reducing/antioxidant power assay. J Agric Food Chem. 47: 633-636.

[31] FAO/WHO, Protein quality evaluation. Report of Joint FAO/WHO Expert Consultation, Bethesda, MD, 4-8 December 1989. FAO/WHO, Rome, Italy, 1990.

[32] Xie, N. N., Wang, C., Ao, J., and Li, B. (2013). Nongastrointestinal-hydrolysis enhances bioavailability and antioxidant efficacy of casein as compared with its in vitro gastrointestinal digest. FOOD RESEARCH INTERNATIONAL. 51: 114-122.

[33] Fang, X. B., Xie, N. N., Chen, X., Yu, H., and Chen, J. (2012). Optimization of antioxidant hydrolysate production from flying squid muscle protein using response surface methodology. FOOD AND BIOPRODUCTS PROCESSING. 90: 676-682.

[34] Zhu, L. J., Chen, J., Tang, X. Y., and Xiong, Y. (2008). Reducing, radical scavenging, and chelation properties of in vitro digests of alcalase-treated zein hydrolysate. J Agric Food Chem. 56: 27142721.

[35] Zheng, L., Ren, J., Su, G., Yang, B., and Zhao, M. (2013). Comparison of in vitro digestion characteristics and antioxidant 
activity of hot- and cold-pressed peanut meals. Food Chem, 141: 4246-4252.

[36] Ma, Y. Y., and Xiong, Y. (2009). Antioxidant and Bile Acid Binding Activity of Buckwheat Protein in Vitro Digests. J Agric Food Chem. 57: 4372-4380.
[37] Xu, C., Liu, S., Liu, Z. Q., Song, F. R., and Liu, S. Y. (2013). Superoxide generated by pyrogallol reduces highly water-soluble tetrazolium salt to produce a soluble formazan: A simple assay for measuring superoxide anion radical scavenging activities of biological and abiological samples. ANALYTICA CHIMICA ACTA. 793: 53-60. 